\title{
Clinical Audit on Management of Community-Acquired Pneumonia in Pediatric Intensive Care Unit
}

\author{
MOHAMMED D. MOHAMMED, M.Sc.; ASMAA H. SHORIET, M.D. and EMAN A.A. ASKAR, M.D. \\ The Department of Pediatrics, Faculty of Medicine, Assiut University, Assiut, Egypt
}

\begin{abstract}
Background: Paediatric respiratory disease is an important cause of morbidity in both the developing as well as the developed world. Community Acquired Pneumonia (CAP) means an infection of the lung caused by multiple microorganisms acquired outside the hospital setting, leading to inflammation of the lung tissue. It is typically associated with fever and respiratory symptoms such as cough and tachypnea, but symptoms may be non-specific in young children. Radiographic changes may be useful to confirm the diagnosis. It remains an important cause of death in children throughout the world, especially in developing countries.
\end{abstract}

Aim of Study: To evaluate the following using the 2011 pediatric CAP guidelines in children admitted in the Pediatric Intensive Care Unit (PICU) in the period from 1 st of January to 31 st of December, 2016 as the reference standard where applicable and try to make Guidline for the management of Community-Acquired Pneumonia in infants and children older than 3 months of age at pediatric Intensive Care Unit (PICU), Assuit University Children Hospital.

Patients and Methods: This study is a clinical audit on management of Community Acquired Pneumonia (CAP) among children admitted in the Pediatric Intensive Care Unit (PICU) in the period from 1 st of January to 31 st of December 2016. Evaluation was done according to the guidelines of Community Acquired Pneumonia (CAP) in infants and children recommended by the Pediatric Infectious Disease Society and the Infectious Diseases Society of America, August, 2011.

Results: Our study was done on children with Community Acquired Pneumonia admitted to the Pediatric Intensive Care Unit (PICU), Assuit University Children Hospital in in the period from 1 st of January to 31 st of December, 2016. Our study included sixty cases of them there were 36 males $(60 \%)$ and 24 females $(40 \%)$. Their ages ranged from 3 months up to 17 years. Fifty five out of sixty cases $(91.7 \%)$ presented with history of fever while fourty five cases $(75 \%)$ presented with history of cough. According to WHO guidelines for criteria of respiratory distress in children with pneumonia the most common sign of respiratory distress was pulse oximetry measurement $<90 \%$ on room air as it was present in fifty two

Correspondence to: Dr. Mohammed D. Mohammed, The Department of Pediatrics, Faculty of Medicine, Assiut University, Assiut, Egypt cases $(86.7 \%)$, followed by tachypnea which was present in fourty four cases $(73.3 \%)$, altered mental status in thirty five cases $(58.3 \%)$, chest retraction in twenty five cases $(41.7 \%)$, grunting was in twenty three cases $(38.3 \%)$, dyspnea in eighteen cases $(30 \%)$. Apnea was present in fifteen cases $(25 \%)$ while there was no case who presented with nasal flaring.

Conclusion: An accurate and rapid diagnosis of the pathogen responsible for CAP provides for informed decision making, resulting in improved care with focused antimicrobial therapy, fewer unnecessary tests and procedures, and, for those who are hospitalized, potentially shorter inpatient stays. Unfortunately, in the diagnosis of CAP, particularly bacterial $\mathrm{CAP}$, there are no single diagnostic tests that can be considered the reference standard.

We decided in this clinical audit to evaluate how will the guidelines have been followed in the acute management of children with Community Acquired Pneumonia at Pediatric Intensive Care. After studying patients admitted at PICU for CAP we found that many points in the 2011 pediatric CAP guidelines was neglected and not followed the most common point was Tracheal Aspirates and it was done for only one case $(1.7 \%)$ while many other points were followed strongly as Pulse Oximetry and Initial Chest Radiographs that were done for $(100 \%)$ of cases.

Key Words: Community acquired pneumonia - Pediatric intensive care unit.

\section{Introduction}

CAP is defined clinically by the presence of signs and symptoms of pneumonia in a child who was completely healthy before the onset of the disease and occured due to an acute infection (less than 14 days duration) of the lower respiratory system. CAP usually occurs below terminal bronchioles leading to cough or difficult breathing, tachypnea, and or lower chest-wall indrawing [1]. A more

\section{Abbreviations : \\ CAP : Community Acquired Pneumonia. \\ PICU : Pediatric Intensive Care. \\ WHO : World Health Organization.}


practical term-Acute Lower Respiratory Infection (ALRI)-is preferred, reflecting the difficulties in obtaining a chest radiograph, especially in rural areas [2].

Pneumonia is the most common cause of death worldwide of children under age of five years. The application of safe, effective and affordable interventions has reduced pneumonia mortality to one million in 2013 after it was 4 million in 1981 [3].

\section{Patients and Methods}

Clinical audit on management of Community Acquired Pneumonia (CAP) among children admitted in the Pediatric Intensive Care Unit (PICU), Assuit University Children Hospital in the period from 1 st of January to 31 st of December, 2016. According to the guidelines of Community Acquired Pneumonia (CAP) in infants and children recommended by the Pediatric Infectious Disease Society and the Infectious Diseases Society of America, August, 2011.

Inclusion criteria: Age older than 3 months, not hospitalized.

Exclusion criteria: Immune deficiency, chronic lung disease (e.g., cystic fibrosis).

\section{The guidline includes:}

Indication of Admission at Pediatric Intensive Care Unit (ICU) or a Unit with continuous cardiorespiratory monitoring:

\section{Major criteria:}

- Need to invasive mechanical ventilation.

- Fluid refractory shock.

- Acute need for Nasal Intermittent Positive Pressure Ventilation (NIPPV).

- Hypoxemia requiring fraction of inspired Oxygen more than inspired concentration or flow feasible in general care area.

\section{Minor criteria:}

- Respiratory rate higher than the WHO classification for age.

- Apnea.

- Signs of respiratory distress (eg, retractions, dyspnea, nasal flaring, grunting).

- $\mathrm{PaO} 2 / \mathrm{FiO}_{2}$ ratio below 250 .

- Multilobar infiltrates.

- Pediatric Early Warning Score (PEWS) more than 6.
- Altered mental status.

- Hypotension.

- Presence of effusion.

- Unexplained metabolic acidosis [4]

- In presence of complicated pneumonia which accompanied with sever respiratory distress or poor general condition [4]

\section{Results}

Demographic data of the studied group:

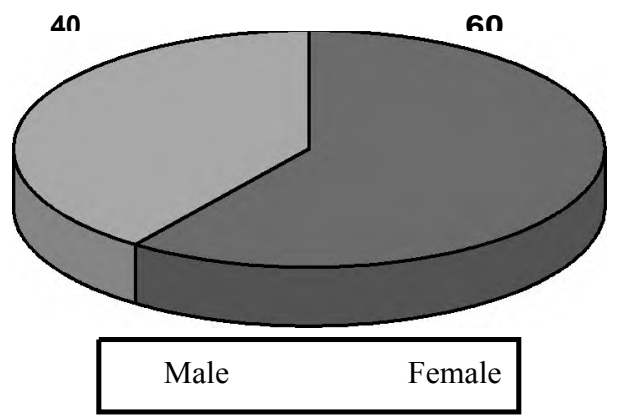

Fig. (1): Sex of studied cases.

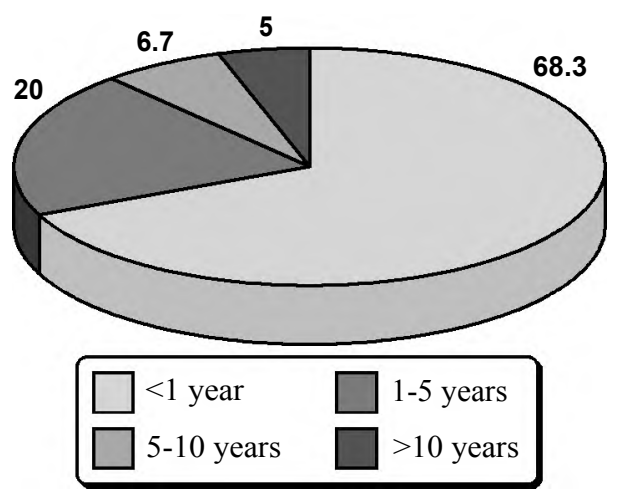

Fig. (2): Age of studied cases.

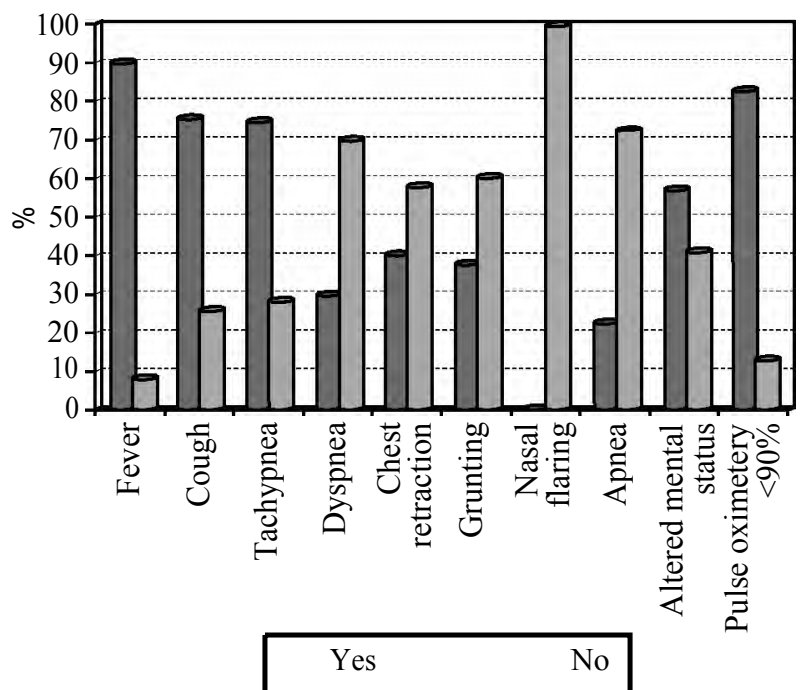

Fig. (3): Percentage frequency of significant items of history and examination among studied cases. 


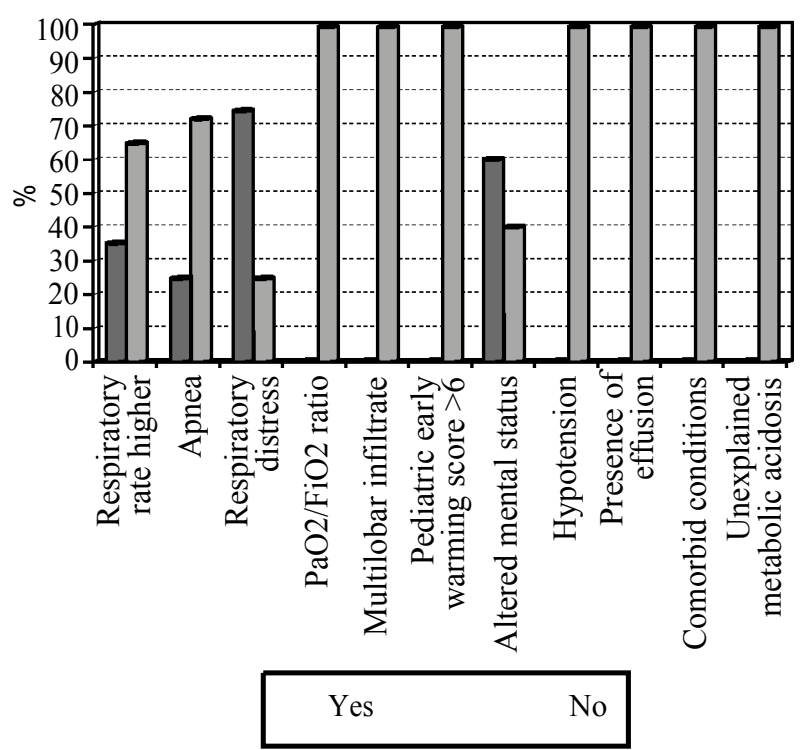

Fig. (4): Minor criteria for admission at Pediatric Intensive Care Unit.

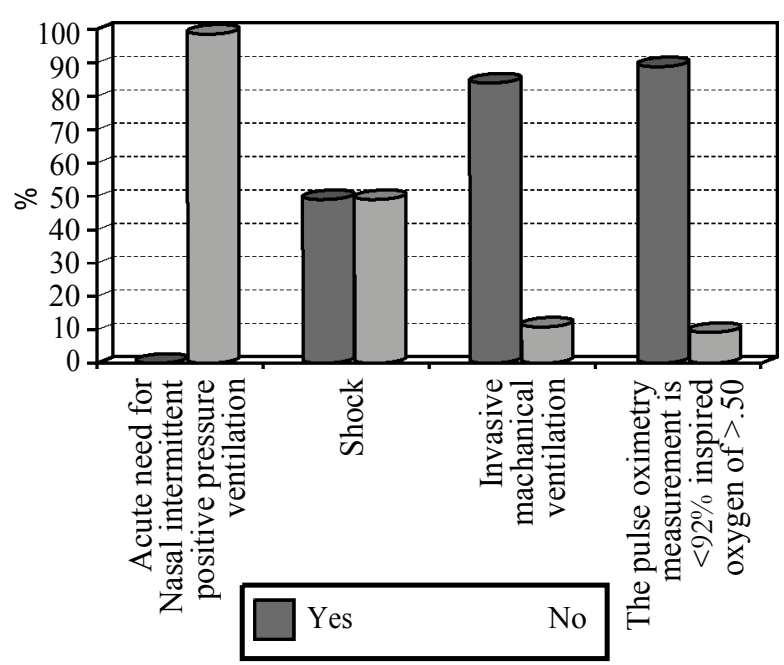

Fig. (5): Major criteria for admission at Pediatric Intensive Care Unit.

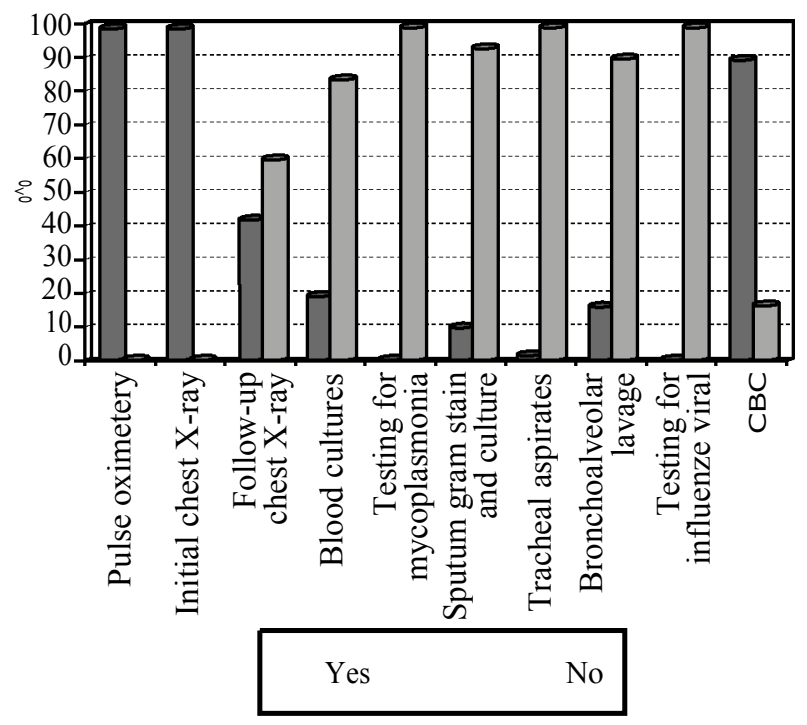

Fig. (6): Diagnostic testing for pediatric CAP.

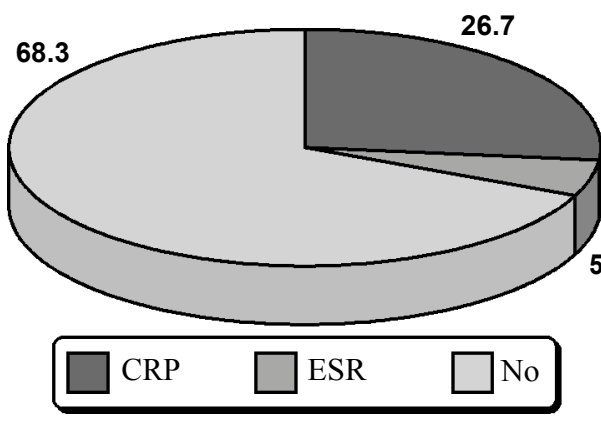

Fig. (7): Acute phase reactant.

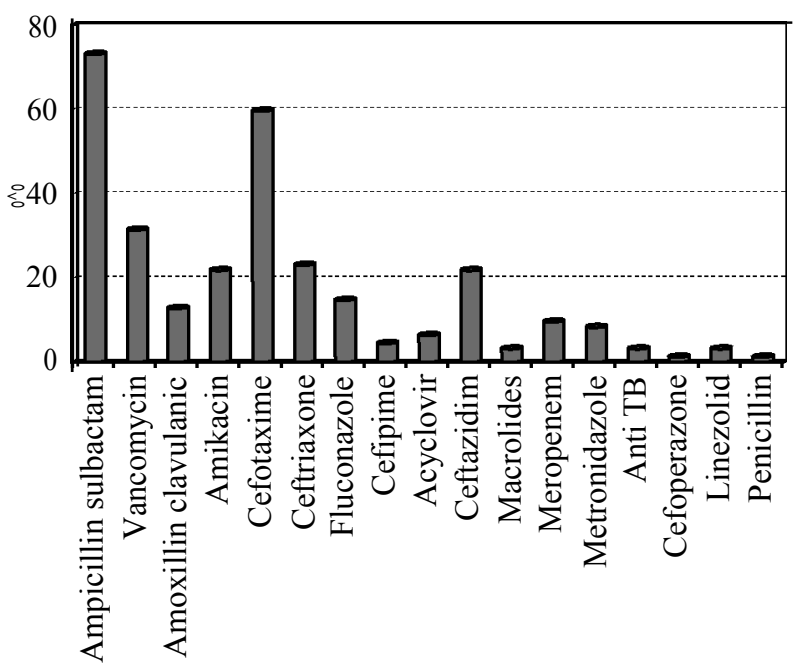

Fig. (8): Antimicrobial therapy.

Table (1): Antimicrobial therapy.

\begin{tabular}{lll}
\hline & No. & $\%$ \\
\hline Ampicillin sulbactam & 44 & 73.3 \\
Vancomycin & 19 & 31.7 \\
Amoxillin clavulanic & 8 & 13.3 \\
Amikacin & 13 & 21.7 \\
Cefotaxime & 36 & 60 \\
Ceftriaxone & 14 & 23.3 \\
Fluconazole & 9 & 15 \\
Cefipime & 3 & 5 \\
Acyclovir & 4 & 6.7 \\
Ceftazidim & 13 & 21.7 \\
Macrolides & 2 & 3.3 \\
Meropenem & 6 & 10 \\
Metronidazole & 5 & 8.3 \\
Anti TB & 2 & 3.3 \\
Cefoperazone & 1 & 1.7 \\
Linezolid & 2 & 3.3 \\
Penicillin & 1 & 1.7 \\
\hline
\end{tabular}

\section{Discussion}

The main purpose of these guidelines is to decrease morbidity and mortality rates of CAP in children by presenting recommendations for clinical management that can be applied in patients if deemed appropriate by the treating stuff. 


\section{Demographic data:}

Our study was done on children with Community Acquired Pneumonia and who were admitted to the Pediatric Intensive Care Unit (PICU), Assuit University Children Hospital in in the period from 1 st of January to 31 st of December, 2016.

Our study included sixty cases of them were 36 males (60\%) and 24 females (40\%). Their ages ranging from 3 months up to 17 years.

\section{According to history and examination:}

Fifty five out of sixty cases $(91.7 \%)$ presented with history of fever while fourty five cases $(75 \%)$ presented with history of cough.

According to WHO guidelines for criteria of respiratory distress in children with pneumonia the most common sign of respiratory distress was pulse oximetry measurement $<90 \%$ on room air and it was present in fifty two cases $(86.7 \%)$, followed by tachypnea which was recorded in fourty four cases $(73.3 \%)$, altered mental status was found in thirty five cases $(58.3 \%)$ and chest retraction was present in twenty five cases $(41.7 \%)$, grunting was present in twenty three cases $(38.3 \%)$, dyspnea in eighteen cases (30\%). Apnea was recorded in fifteen cases $(25 \%)$ while there was no case who presented with nasal flaring.

Accordig to Indication of admission at Pediatric Intensive Care Unit:

\section{Minor criteria:}

Respiratory distress was present in fourty five cases $(75 \%)$, altered mental status in thirty five cases $(58.3 \%)$, respiratory rate greater than $\mathrm{WHO}$ classification for age was found in twenty cases $(33.3 \%)$ and apnea was recorded in fifteen cases $(25 \%)$.

There was no case with $\mathrm{PaO} 2 / \mathrm{FiO} 2$ ratio below 250 nor multilobar infiltrates nor Pediatric Early Warning Score (PEWS) more than 6 nor presence of effusion nor comorbid conditions nor unexplained metabolic acidosis.

\section{Major criteria:}

The pulse oximetry measurement is $<92 \%$ inspired oxygen of $>.50$ was the most common indication of admission to the the Pediatric Intensive Care Unit (PICU) as it was present in fifty two cases $(86.7 \%)$ while fifty one cases $(85 \%)$ required invasive ventilation via a nonpermanent artificial airway (eg, endotracheal tube). Shock was present in thirty cases $(50 \%)$ but there was no case who needed nasal intermittent positive pressure ventilation.

According to diagnosis testing for pediatric CAP:

Pulse oximetry and initial chest radiographs were done for sixty cases (100\%) while follow-up chest radiographs was done for twenty five cases $(41.7 \%)$.

Complete Blood Count (CBC) was the commonest laboratory test as it was done for fifty two cases (86.7), other laboratory tests were used as CRP was done for sixteen cases $(26.7 \%)$ while ESR was done for three cases (5\%) and blood cultures were done for ten cases $(16.7 \%)$.

Bronchoalveolar Lavage (BAL) was done for eight cases (13.3\%) while Sputum gram stain and culture was done for five cases $(8.3 \%)$ but Tracheal Aspirates was done for only one case (1.7\%).

Testing for mycoplasma and testing for influenza viral were not done for any case.

\section{According to antimicrobial therapy:}

All cases received combined empiric antimicrobial therapy. Ampicillin sulbactam was the commonest empiric antimicrobial therapy as fourty four cases $(73.3 \%)$ received it followd by cefotaxime in thirty sex $(60 \%)$, nineteen cases received vancomycin (31.7\%), fourteen cases (23\%) received ceftriaxone.

Thirteen cases $(21.7 \%)$ received amikacin, also ceftazidim was received in thirteen cases $(21.7 \%)$.

Nine cases $(15 \%)$ received Fluconazole, eight cases (13.3\%) received Amoxicillin Clavulanic, six cases $(10 \%)$ received Meropenem, five case $(8.3 \%)$ received Metronidazole, four cases $(6.7 \%)$ received Acyclovir while three cases $(5 \%)$ received Cefipime.

Two cases $(3.3 \%)$ received Macrolides, also Anti TB and linezolid were received in two cases.

Only one case $(1.7 \%)$ received Cefoperazone and one case received penicillin.

\section{References}

1- ZAR H.J., JEENA P., ARGENT A., GIE R. and MADHI S.A.: Diagnosis and management of community acquired pneumonia in childhood- South African Thoracic Society Guidelines. S. Afr. Med. J., 95: 977-90, 2005.

2- British Thoracic Society Standards of Care Committee: BTS Guidelines for the Management of Community Acquired Pneumonia in Childhood. Thorax, 57: 1-24, 2002. 
3- Global Health Observatory: Proportions of child deaths by cause. (http://www.who.int/gho/child_health/ en/index. html), WHO, Geneva Accessed on 24 July 2014.

4- BRADLEY J.S., BYINGTON C.L., SHAH S.S., ALVERSON B., CARTER E.R., et al.: The management of com- munity-acquired pneumonia in infants and children older than 3 months of age; clinical practice guidelines by the Pediatrie Infectious Diseases Society and the Infectious Diseases Society of America. Clin. Infect. Dis., 53: e2576, 2011.

\section{دراسة تدقيقية فى تشخيص وعلاج الإلتهاب الرئوى المكتسب فى وحلدة العناية الهركزة للآطفال}

الإلتهاب الرئوى المكتسب من المجتمع هو السبب الاكثر شيوعا للوفاة فى الآطفال فى جميع آنحاء العالم، وهو آيضا التشخيص الآكثر

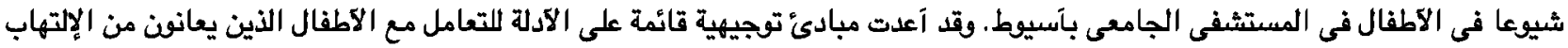

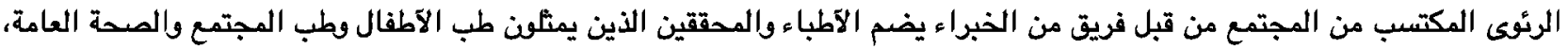

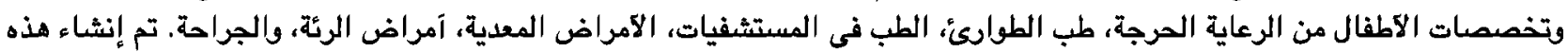

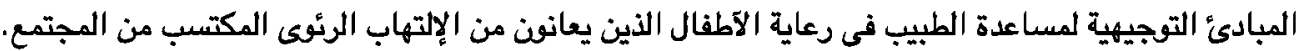

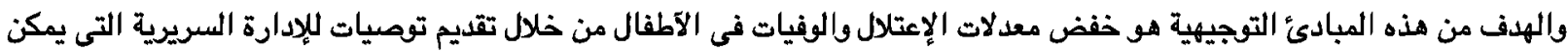

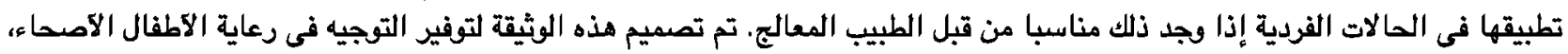

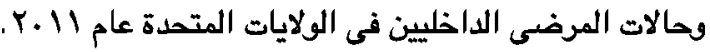

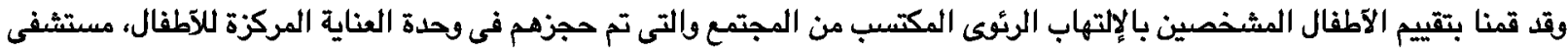

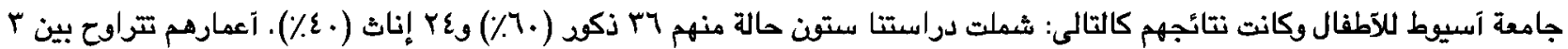

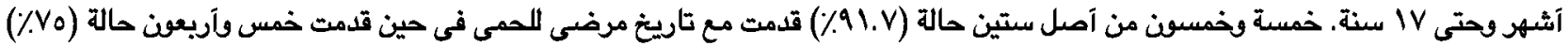

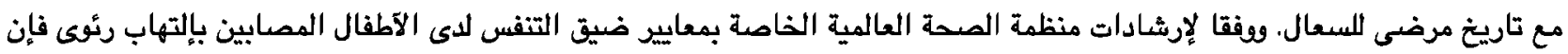

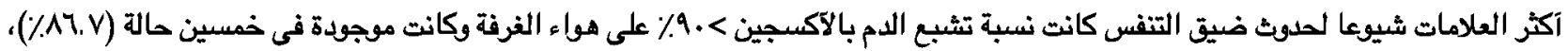

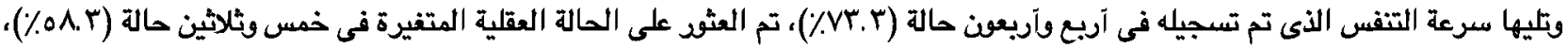

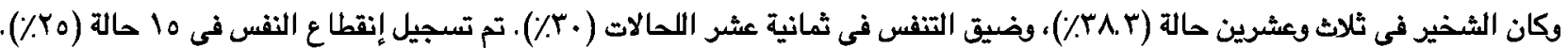
تم إجراء نسبة تشبع الآكسين بالدم والتصوير بالآشعة السينية الآولى على الصدر لستين حالة (. (1٪) بينما تم إجراء متابعة بالتصوير بالآشعة السينية فى خمس وعشرين حالة (VI.V٪).

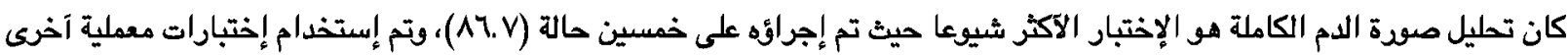

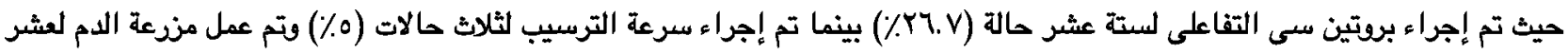

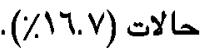

